DOI: $10.1590 /$ permusi2015a3109

\title{
Suíte № 1 para violoncelo solo de Max Reger e a escrita de J.S. Bach: relações de dependência e identidade de linguagem
}

\author{
Ângela Maria Ferrari (UFSM, Santa Maria - RS) \\ angferrari2003@yahoo.com.br
}

\author{
Felipe Avellar de Aquino (UFPB, João Pessoa - PB) \\ felipecello@hotmail.com
}

Resumo: O presente trabalho busca demonstrar como Max Reger emprega modelos de J.S. Bach na construção de sua Suíte № 1, Op. 131c. Dessa forma, em sua escrita, Reger combina elementos da harmonia do final do século XIX com técnicas contrapontísticas de J.S. Bach. A influência do mestre barroco é visualizada desde a escolha das tonalidades até a utilização de motivos que são, de fato, transformações e expansões de motivos "bachianos". Portanto, este trabalho discute as técnicas de composição empregadas por Reger na Suíte Op. 131c no 1, como também traça um paralelo entre essa obra, em particular, com movimentos das suítes para violoncelo solo de J.S. Bach. Respaldado pela linguagem baseada no cromatismo, Reger resgata, ao mesmo tempo, o gênero Suíte na literatura solo do violoncelo, e sob a égide da estética do romantismo tardio, cria uma obra com características e estilo próprios. A partir dessas premissas, o trabalho propõe subsidiar o intérprete em suas decisões interpretativas.

Palavras Chave: Max Reger; J.S. Bach; suíte para violoncelo solo; práticas interpretativas.

Max Reger's Suite $N^{0} 1$ for violoncello solo and the writings of J.S. Bach: dependence relations and language identity

Abstract: This article aims at demonstrating how Max Reger employs musical patterns of J. S. Bach as models for the construction of his Suite Op. 131c no 1 for cello solo. Thus, in his compositions Reger combines harmonic elements from the end of the 19th century with contrapuntal techniques of J. S. Bach. The influence of the German master can be traced from the choice of tonalities to the use of motives, which are, in fact, expansions and transformations of "bachian" motifs. Consequently, this article discusses the compositional techniques employed by Reger in the Suite Op. 131c $n^{-1}$ for cello solo. It also draws a parallel between this particular composition and movements from J. S. Bach's cello suites. Endorsed by a compositional language based on chromaticism, Reger redeems the Suite as a genre for the cello solo literature and, at the same time, under the aegis of the late romantic aesthetic, he creates a work with unique style and characteristic. Based on these premises, this work aims to support the performer in her/his musical decisions.

Keywords: Max Reger; J.S. Bach; suite for cello solo; performance practices.

\section{Introdução}

A obra de Max Reger (1873-1916) representa, em muitos aspectos, a continuidade da tradição musical alemã, visto que o desenvolvimento de sua estética e linguagem musical foi notadamente influenciado por J.S. Bach e J. Brahms. Autor de vasta produção, toda elaborada no intervalo de apenas 26 anos, Reger conseguiu combinar elementos da harmonia do final do século XIX - os quais beiram a dissolução do sistema tonal - com técnicas contrapontísticas de J.S. Bach. Segundo GRIM (1988, p.5, tradução nossa): 
O aspecto contrapontístico da música de Reger é característica particularmente reconhecível. Provavelmente, nenhum outro compositor alemão do romantismo tardio foi influenciado pela música de Bach como o foi Reger. ${ }^{1}$

Por outro lado, faz-se necessário assinalar que, apesar das composições de Reger serem inovadoras no aspecto tonal, estas não transpõem as fronteiras da tonalidade. Nesse sentido, BRINKMANN (2004, p.637, tradução nossa) afirma que "apesar de estar trilhando o seu próprio caminho cromático, parafraseando as suas próprias palavras 'fielmente em direção à esquerda' ele nunca quis ultrapassar a fronteira para dentro do novo território da atonalidade". 2 Sendo assim, constata-se em suas obras uma linguagem moderna e inovadora, ainda que dentro da estética do Romantismo tardio. Porém, a música de Reger é estruturada de maneira a preservar os ensinamentos dos mestres do passado, uma vez que "é ele quem constrói uma linguagem modernista, detendo e, ao mesmo tempo, relativizando os princípios musicais do passado" (FRISH, 2004, p.742, tradução nossa). ${ }^{3}$

As Suítes para violoncelo solo Op. $131 \mathrm{c}$ se constituem em exemplos de como Max Reger emprega elementos da escrita bachiana nas suas composições e, ao mesmo tempo, consegue se distanciar do mestre para realizar algo genuinamente seu. É, portanto, intuito deste artigo discutir as técnicas composicionais empregadas por Reger na Suíte Op. $131 \mathrm{c} n^{\circ}$ 1, como também traçar um paralelo entre essa obra, em particular, com movimentos das suítes para violoncelo solo de J.S. Bach. Desta forma, será demonstrado ao longo deste trabalho que Reger encontra na escrita contrapontística de Bach diversas referências composicionais.

Na catalogação da obra de Max Reger, o conjunto de composições agrupadas como Op. 131 compreende obras para violino solo (Seis Prelúdios e Fugas para Violino Solo, Op. 131a), duo de violinos (Três Duos-Cânones e Fugas em "Estilo Antigo" para Duo de Violinos, Op. 131b), violoncelo solo (Três Suítes, Op. 131c para Violoncelo Solo) e, por fim, viola solo (Três Suítes Op. 131d para Viola Solo).

De acordo com os registros catalográficos, as obras Op. 131a e 131b foram escritas em 1914. Por outro lado, as Suítes para violoncelo solo (Op. 131c) e viola solo (Op. 131d) foram concluídas no ano seguinte, ou seja, 1915. Ressalta-se, no entanto, que o Op.131c é composto por três suítes, sendo que as Suítes $n^{\circ} 1$ e $n^{\circ} 3$ apresentam três movimentos, enquanto a Suíte $n^{\circ} 2$ possui quatro movimentos, conforme demonstrado no Ex.1.

\begin{tabular}{|c|c|c|}
\hline Obra & Tonalidade & Movimentos \\
\hline Suíte I & Sol Maior & Präludium/Adagio/Fuge \\
\hline Suíte II & Ré Menor & Präludium/Gavotte/Largo/Gigue \\
\hline Suíte III & Lá Menor & $\begin{array}{c}\text { Präludium /Scherzo/Andante con } \\
\text { Variazioni }\end{array}$ \\
\hline
\end{tabular}

Ex.1: Tabela - Estrutura das Suítes Op. 131c de Max Reger 
É interessante notar que essas composições foram dedicadas a três eminentes violoncelistas/professores, representantes da escola germânica do violoncelo de então: Julius Klengel (1859-1933), Hugo Becker (1863-1841) e Paul Grümmer (1879-1965). Sobre os dois primeiros, JOHNSTONE (acesso em 25 março 2011, tradução nossa) em seu artigo "The late-romantic German cello school - an introduction to Julius Klengel and his compositions", sustenta que:

\begin{abstract}
Além de serem reconhecidos como excelentes solistas e cameristas, eles viriam a se tornar os mais proeminentes professores de violoncelo durante os primeiros trinta anos do século $\mathrm{XX}$, apesar de diferentes metodologias e opiniões sobre como ensinar. Pode-se dizer que eles se constituem em dois expoentes na arte germânica do violoncelo. ${ }^{4}$
\end{abstract}

Além do mais, esses violoncelistas tiveram contato direto com Max Reger. De fato, e como afirma GINSBURG (1983, p.76, tradução nossa), "Reger dedicou a Klengel uma das suas suítes para violoncelo solo, Op. 131, № 1, e a sonata para violoncelo e piano Op. 116. Reger também tocou frequentemente com o violoncelista". 5

Por sua vez, Paul Grümmer foi aluno de Klengel e também muito respeitado em seu tempo. Dessa maneira, tem-se a Suíte $n^{o} 1$ dedicada a Julius Klengel, a $n^{\circ} 2$ a Hugo Becker e, finalmente, a $n^{\circ} 3$ dedicada a Paul Grümmer. Salientase que Klengel revisou e publicou, na qualidade de editor, uma versão das Seis Suítes de Bach para violoncelo solo. É também atribuído a Klengel o mérito de ter realizado a tarefa de tornar as suítes de Bach conhecidas e estudadas por seus alunos. Muitos desses discípulos, por sua vez, tornaram-se expoentes do violoncelo ao longo do século XX. A título de exemplo, citam-se Emanuel Feuermann, Guilhermina Suggia, Gregor Piatigorsky, William Pleeth e, como afirmado anteriormente, Paul Grümmer. É possível, portanto, que essa estreita ligação entre Klengel e as Seis Suítes de Bach tenha influenciado Max Reger a dedicar a primeira suíte a esse violoncelista. ${ }^{6}$

Conforme visto no Ex.1, as Suítes de Reger estão nas tonalidades de Sol Maior, Ré Menor e Lá Menor, respectivamente. A partir da reflexão acerca da escolha das tonalidades, é possível traçar uma relação com as Suítes para violoncelo solo de J.S. Bach, uma vez que as Suítes Op. 131 c no 1 e $n^{\circ} 2$ são escritas exatamente nas mesmas tonalidades das duas primeiras suítes de Bach. Por outro lado, a terceira Suíte de Bach foi escrita na tonalidade de Dó Maior, ao passo em que a correspondente de Reger (Op. 131c no 3) está estruturada na tonalidade de Lá Menor, ou seja, na tonalidade relativa menor de Dó Maior. Portanto, verifica-se certo paralelismo entre a escolha tonal dessas obras e as Suítes de Bach.

Ademais, ressalta-se também a vertente "neoclássica" presente na escrita de Reger, como comenta GINSBURG, (1983, p.304, tradução nossa) em relação à importância desse conjunto de obras dentro do repertório violoncelístico. Segundo o autor, "hoje, as três suítes Op. 131 (1915) de Reger, que graficamente revelam as tendências neoclássicas do compositor, são mais frequentemente tocadas do que suas sonatas". 
Mais uma vez remetendo-se ao Ex.1 e como já anteriormente afirmado, o conjunto de obras Op. $131 c$ está estruturado a partir de um modelo com três movimentos - Suítes no 1 e 3 - ou de 4 movimentos, como é o caso da Suíte $n^{\circ}$ 2. Dentre essas, a Suíte $n^{\circ} 1$ tem seus movimentos intitulados Präludium, Adagio e Fuge. Observa-se, todavia, que Reger reelabora o conceito de suíte, em detrimento de uma suposta coletânea de danças - conforme o conceito preestabelecido de suíte barroca. Dessa forma, nessa suíte em particular, o que se segue após o prelúdio são movimentos transmutados, discriminados como Adagio e Fuge. No entanto, pode-se seguramente afirmar que, no movimento de abertura, Reger faz referências, em vários aspectos, ao Prelúdio da Suíte BWV 1007 de J.S. Bach, como será demonstrado a seguir.

\title{
2. Primeiro Movimento: Präludium
}

Assim como nas Seis Suítes para violoncelo solo de Bach, o prelúdio tem a função de movimento de abertura que antecede uma coletânea de danças ou mesmo uma sequência de movimentos. Comparando-se o desenho rítmico do tema do Präludium de Reger, construído a partir de semicolcheias contínuas, como também alguns dos seus contornos melódicos, verifica-se que esses são claramente inspirados no Prelúdio da Suíte no 1 BWV 1007. De certa forma, ao empregar gestos do Prelúdio de Bach, aliados a elementos próprios, notadamente resultantes de sua linguagem harmônica, Reger expande os gestos e motivos bachianos, o que resulta em frases mais extensas. Esse aspecto pode ser visualizado no exemplo abaixo.

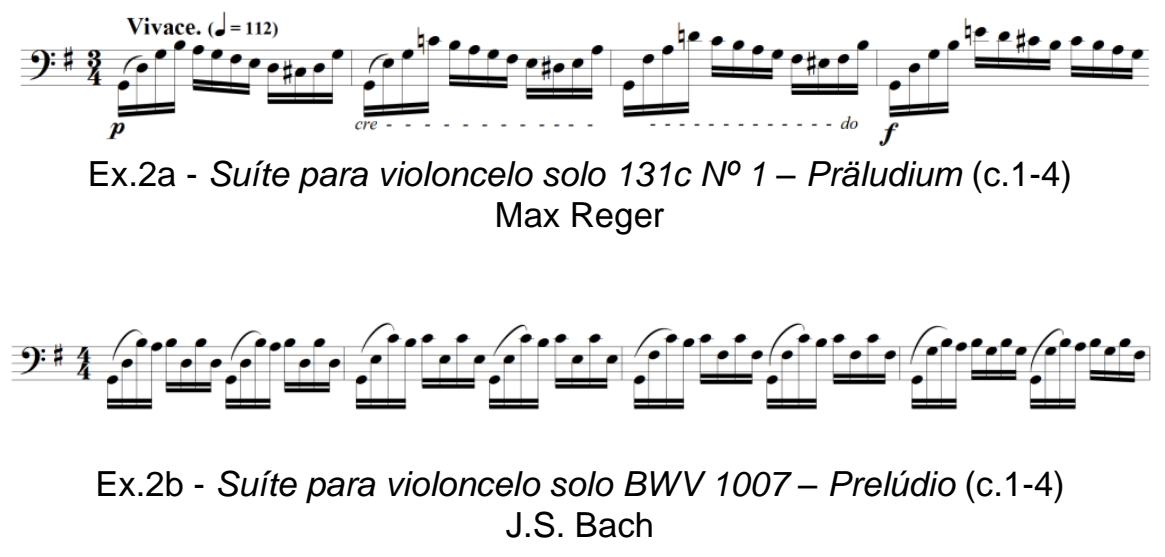

Por definição, o prelúdio é considerado um movimento originalmente de caráter improvisatório, escrito em um estilo livre. Segundo LEDBETTER e FERGUSON (acesso em 25 março de 2011, tradução nossa):

\begin{abstract}
O motivo de se escrever improvisação era geralmente o de prover modelos para estudantes. Essa prática, normalmente visando um aspecto particular da técnica instrumental, se dava de maneira instrutiva e permaneceu parte importante do prelúdio. Uma vez que a improvisação pode abranger um leque de maneiras, estilos e técnicas, o termo foi, posteriormente, aplicado a uma variedade de protótipos formais e a peças de gênero indeterminado. ${ }^{7}$
\end{abstract}

Até certo ponto, pode-se idealizar que Reger concebe o Präludium como se fora uma improvisação a partir de gestos das Suítes de Bach - na verdade, uma transformação do motivo - sob uma nova roupagem harmônica. 
Por outro lado, Max Reger estabelece uma forma bastante clara para o movimento em questão, já que está estruturado na forma $A B A^{\prime}$, distanciandose, assim, do modelo de Bach. Observa-se, então, uma primeira seção $A$ compreendida entre os c.1-28, seção $B$ que se inicia a partir do último tempo do c. 28 até o c. 51 e, por fim, a partir do c. 52 , verifica-se o retorno da seção $A$ - aqui chamada de A'. No entanto, a partir do c. 63, tem-se uma combinação de cordas duplas, material que aparece na seção $B$, e também da textura em semicolcheias predominantes na seção A.

A seção A cadencia em Mi Menor (vi), ou seja, na tonalidade relativa menor de Sol Maior. Por outro lado, a seção B é intensamente cromática. Nota-se que a partir do c.44, Reger, ao empregar cromatismos e arpejos diminutos, encaminha este movimento para a tonalidade de Sol Maior, ou seja, o retorno de A'. Claramente, no c. 52 verifica-se o retorno do desenho inicial do Präludium que se estende até o c. 62.

Como mostra o Ex.3, a partir do terceiro tempo do c.28 até o c.39, portanto dentro da seção $B$, verifica-se uma sequência em cordas duplas que se inicia em Dó Maior. Pode-se traçar um paralelo a essa seção (28 -39) no c.63 o qual, após uma clara modulação para Ré Maior, apresenta uma interpolação, com essa mesma textura, através de uma nova sequência em cordas duplas (c.6370).

\begin{tabular}{|l|c|c|c|}
\hline \multicolumn{1}{|c|}{ Seção } & A & B & A $^{\prime}$ \\
\hline Compassos & $1-28$ & 28 (último tempo) -51 & $52-82$ \\
\hline Emprego de Cordas Duplas & & 28 (último tempo) - 39 & $63-70$ \\
\hline
\end{tabular}

Ex.3: Tabela - Estrutura do Präludium e o emprego de múltiplas vozes

Outra característica empregada por Bach no Prelúdio da Suíte no 1 BWV 1007, e explorada de maneira semelhante por Reger, consiste na estratégia de escrever a linha melódica alternando-se a uma nota pedal em corda solta, com a finalidade de se construir e intensificar um ponto de tensão (Ré no c.12 e Sol no c.13 - portanto, uma relação de $5^{a}$ descendente), como pode ser visto no Ex.4a. Comparando-se os dois Prelúdios, verifica-se que Bach emprega esse artifício por oito compassos (c.31 a 38) ao conduzir o Prelúdio para seu final. Dessa forma, a linha melódica é desenhada sobre o pedal da corda solta - Lá (c.31-36), seguido pelo pedal de dominante - Ré (c.37-38). Bach também explora a mesma relação de $5^{\text {a }}$ descendente nas notas pedais, o que harmonicamente se constitui em um pedal de dominante (Ex.4b). Nota-se, no entanto, que se trata de uma combinação de bariolage e brisure, duas técnicas de arco amplamente empregadas na música do século XVIII e que são aqui resgatadas por Reger.

Reger utiliza esse gesto para se distanciar da tonalidade de Ré Maior, apresentada nos c.10 e 11, enquanto Bach o utiliza como meio para atingir o final do Prelúdio e o acorde de tônica - Sol Maior. 


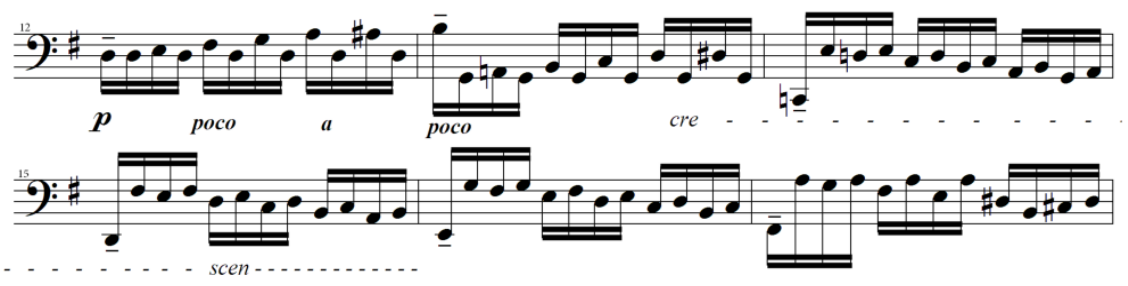

Ex.4a - Suíte para violoncelo solo 131c № 1 - Präludium (c.12-17) Max Reger

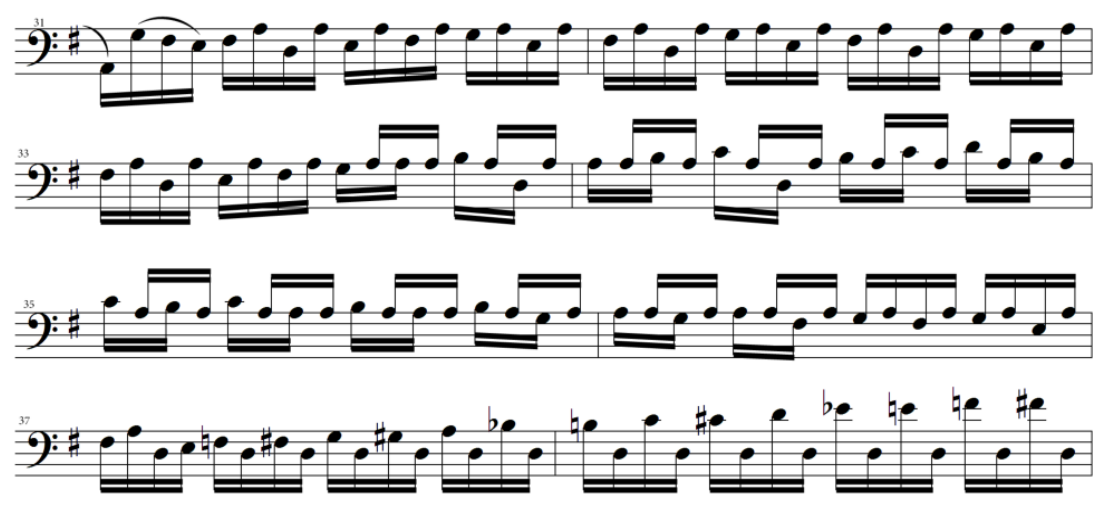

Ex.4b - Suíte para violoncelo solo BWV 1007 - Prelúdio (c.31-38) J.S. Bach

Ademais, como profundo conhecedor da obra do mestre alemão, Reger possivelmente baseou-se não somente em características da Suíte no 1 , mas também incorporou elementos e gestos musicais de outras das Seis Suítes de Bach para compor sua obra para violoncelo solo. Sendo assim, considera-se que há nítida influência do gesto de abertura do Prelúdio da Suíte no 3 de Bach (BWV 1009) sobre as inflexões presentes nos c.10-11 e c.61-62 no Präludium de Reger.

A fim de estabelecer claramente a tonalidade, Bach inicia a Suíte para violoncelo solo BWV 1009 com um gesto marcante, formado por uma escala descendente, seguido por um arpejo na tônica (Ex.5a). Reger, por outro lado, emprega uma variante desse mesmo gesto (Ex.5b), em dois momentos distintos do Präludium. Nos c.10-11 estabelece a tonalidade da dominante, em momento que precede o distanciamento da tonalidade, através do uso de uma série de sequências. Reger emprega esse gesto uma última vez, na tonalidade da tônica, (c.82-83) a fim de concluir o movimento em Sol Maior (Ex.5c).

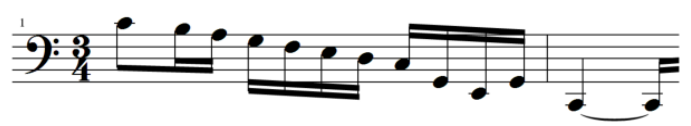

Ex.5a - Suíte para violoncelo solo BWV 1009 - Prelúdio (c.1-2) J.S. Bach 


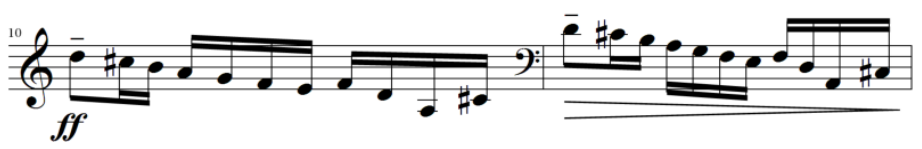

Ex.5b - Suíte para violoncelo solo 131c № 1 - Präludium (c.10-11) Max Reger

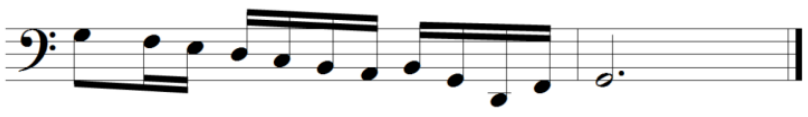

Ex.5c - Suíte para violoncelo solo 131c № 1 - Präludium (c.82-83) Max Reger

Nota-se que, ao contrário do Prelúdio BWV 1007 de Bach, em que a tonalidade de Ré Maior aparece de forma contundente na seção intermediária (c.22), como ponto de chegada, Reger afirma a tonalidade da dominante nos c.10 e 11, uma vez que, nessa linguagem, o movimento harmônico é bem mais ágil.

\begin{tabular}{|l|c|c|}
\hline & Bach & Reger \\
\hline \multirow{2}{*}{ Compassos } & 22 & $10-11$ \\
\cline { 2 - 3 } & & $61-62$ \\
\hline
\end{tabular}

Ex.6: Tabela - Estabelecimento da tonalidade (Ré Maior)

Por fim, nos cinco últimos compassos, Reger emparelha e confronta esses dois gestos enfáticos e marcantes de Bach, que, como afirmado, são provavelmente extraídos dos Prelúdios das Suítes BWV 1007 e 1009, respectivamente. Têmse então, inflexões formadas pelo arpejo de Sol Maior, oriundo da Suíte $n^{\circ}$ 1, em justaposição ao gesto escalar descendente que culmina no arpejo característico do início, como também do final da Suíte $n^{\circ} 3$. Esse confronto marca os cinco compassos conclusivos do Präludium.

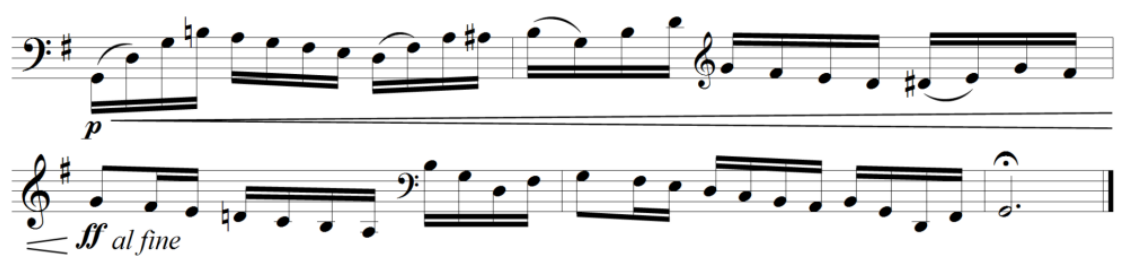

Ex.7 - Suíte para violoncelo solo 131c № 1 - Präludium (c.79-83) Max Reger

\section{Segundo Movimento: Adagio}

O segundo movimento da Suíte Op. $131 c n^{\circ} 1$ é um Adagio em compasso ternário simples e, em parte, escrito em múltiplas vozes. Essa textura, embora encontrada nos outros movimentos, remete particularmente às Sarabandas das Suítes de Bach. Nestas, notamos o uso constante de múltiplas vozes com ênfase e apoio métrico no segundo tempo do compasso. Essa escrita, de certa forma, torna o movimento complexo em seu aspecto técnico e musical (Ex.8). 
De acordo com LITTLE e JENNE, (1998, p.106, tradução nossa), "Todas as seis suítes de Bach contêm sarabandas, e cada uma constitui-se em contribuição única para a literatura do instrumento. ${ }^{8}$ Por sua vez, GITTER, (2009, p.4, tradução nossa) afirma que:

Durante o período do barroco tardio (início de 1700), a polifonia no violoncelo era limitada principalmente às peças mais lentas, onde havia mais tempo para resolver os desafios técnicos envolvidos na sustentação de múltiplas vozes, como é o caso da Sarabanda da Suíte No. 4 em Mi-bemol maior, BWV. 1010 para violoncelo solo de J. S. Bach. ${ }^{9}$
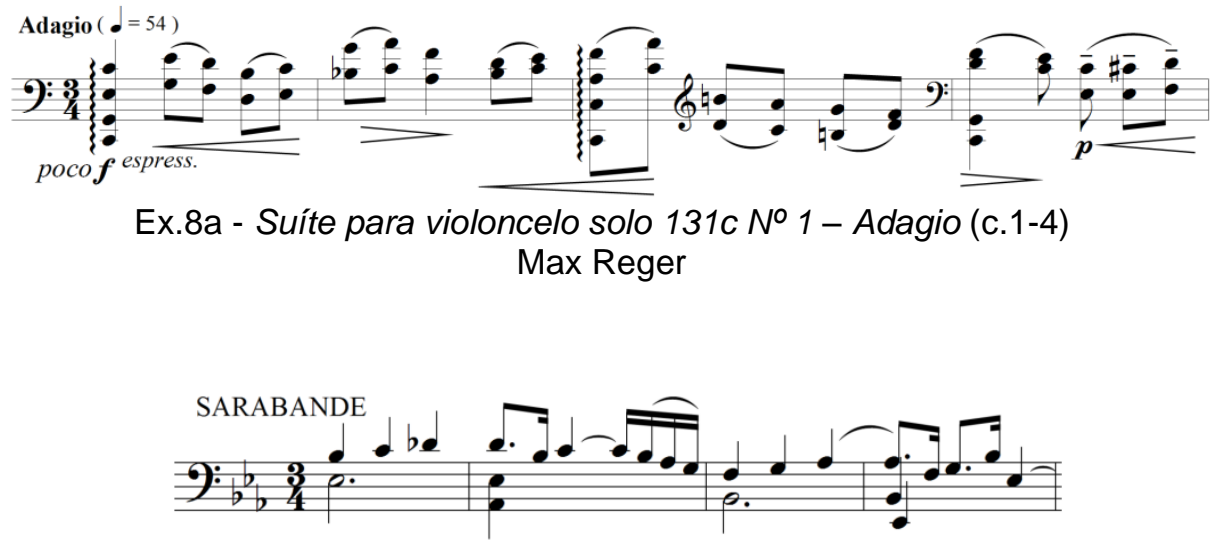

Ex.8b - Suíte para violoncelo solo BWV 1010 - Sarabanda (c.1-4) J.S. Bach

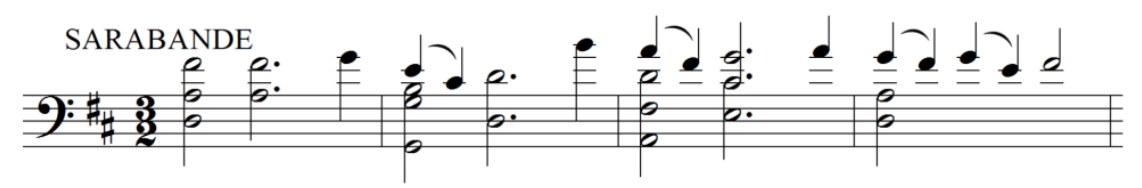

Ex.8c - Suíte para violoncelo solo BWV 1012 - Sarabanda (c.1-4) J.S. Bach

Igualmente, consideramos que o segundo movimento da Suíte de Reger faz alusão à Sarabanda da Terceira Suíte de Bach, também escrita em Dó Maior. No Adagio, nota-se que tanto 0 acorde inicial quanto o gesto final correspondem aos respectivos momentos da Sarabanda de Bach. Reger realiza esses gestos, tanto no início quanto no final do movimento, a fim de afirmar a tonalidade de Dó Maior como centro gravitacional, apesar de utilizarse de extenso cromatismo que eventualmente conduz a tonalidades distantes. No primeiro compasso, Reger apresenta um motivo que pode ser reduzido ao gesto Dó-Si-Dó, visto como uma variante do motivo empregado por Bach no primeiro compasso da Sarabanda BWV1009, que é constituído por Dó-Dó-Si (Ex.9a, 9b).

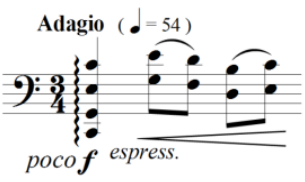

Ex.9a - Suíte para violoncelo solo 131c № 1 - Adagio (c.1) Max Reger 


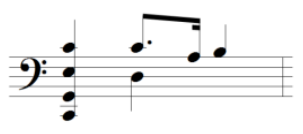

Ex.9b - Suíte para violoncelo solo BWV 1009 - Sarabanda (c.1) J.S. Bach

Por sua vez, considera-se o primeiro tempo do último compasso do Adagio uma ornamentação cromática em torno da nota Sol $(V)$ que conclui em Dó Maior. Na Sarabanda da Suíte BWV 1009, da mesma forma, verifica-se esse movimento do Sol (V) concluindo no acorde de Dó Maior (Ex.10).

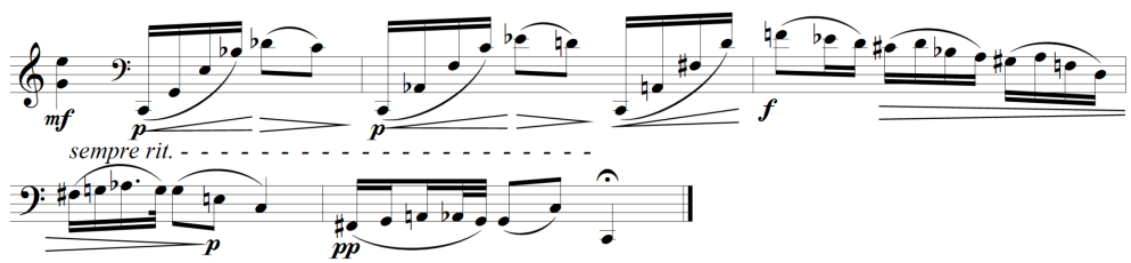

Ex.10a - Suíte para violoncelo solo 131c № 1 - Adagio (c.58-62)

Max Reger

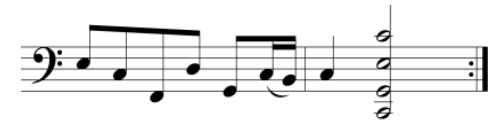

Ex.10b - Suíte para violoncelo solo BWV 1009 - Sarabanda (c.23-24)

J.S. Bach

No entanto, apesar das referências a J.S. Bach, Reger se mantém fiel à sua concepção de escrita e linguagem, também no Adagio. Nesse aspecto, ressalta-se o uso intenso de cromatismo como recurso usual de seu estilo composicional. Segundo NAGLEY e ANDERSON (acesso em 25 março 2011, tradução nossa):

Seu entusiasmo por cromatismo era tal que Schoenberg suspeitou que ele logo fosse se unir às legiões de atonalistas, mas para Reger cromatismo era um meio de expandir as possibilidades da tonalidade, não prenúncio de seu eminente colapso. ${ }^{10}$

A título de ilustração, como mostra o Ex.11, entre os c.53-55 há claramente o emprego, nas notas mais graves, de uma linha cromática que se move da nota Si bemol até a nota Fá natural. 


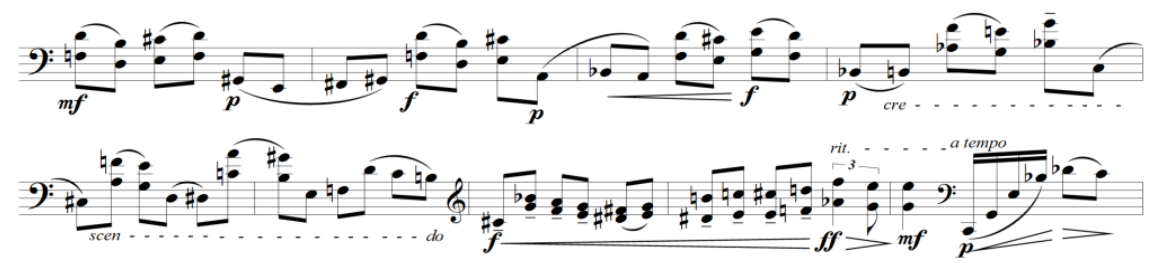

Ex.11 - Suíte para violoncelo solo 131c № 1 - Adagio (c.50-58) Max Reger

Em Reger, não encontramos o indicativo de dança, sarabanda, por extenso, uma vez que ele nomina esse movimento de "Adagio" - aspecto que indica apenas caráter e andamento. Ainda assim, é possível visualizar traços oriundos da referida dança, como também algumas características marcantes da mesma. As Sarabandas das Suítes para violoncelo solo de Bach são consideradas como o movimento lento dessas composições e dessa maneira interpretadas. De fato, a sarabanda, uma dança originariamente de andamento rápido, ao longo do tempo torna-se dança lenta com "caráter completamente distinto, mais calmo, sério e nobre" (CAMPOS, 2010, p.32). Nesse sentido, LITTLE e JENNE (1998, p.106, tradução nossa) afirmam que "o compasso 3/2 novamente nos sugere uma performance lenta e majestosa". ${ }^{11}$

Ao observamos a escrita de Reger, notamos uma estilização dos acentos típicos da sarabanda, no segundo tempo do compasso, como também a presença de acordes que, na sua grande maioria, se desenvolvem em pequenos blocos. Esse gesto, muito significativo, está compreendido entre os c.32 a 38, mais especificamente nos c.32, 33 e 36 . Esses compassos, escritos com a indicação de dinâmica ff (fortíssimo), são marcados pelo deslocamento, por meio da síncope, do acento característico das sarabandas barrocas (Ex.12).

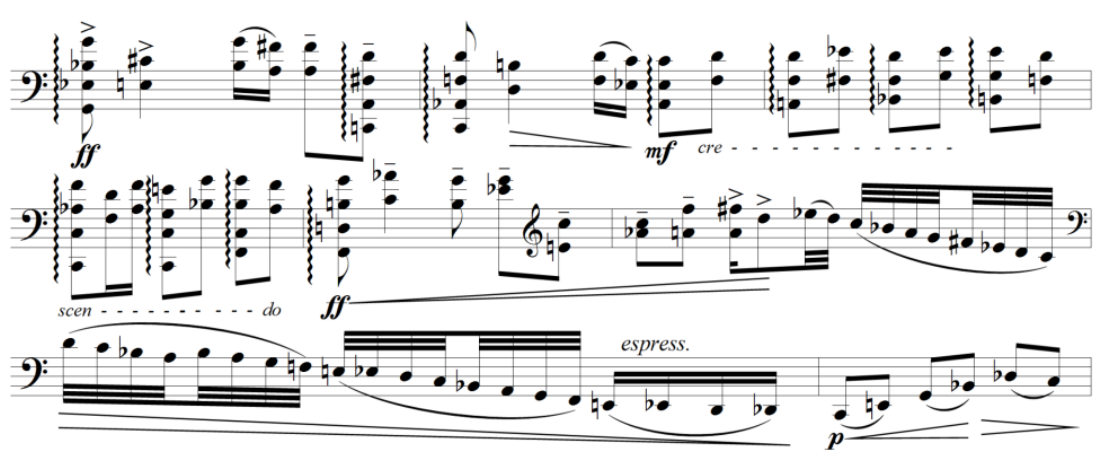

Ex.12 - Suíte para violoncelo solo 131c № 1 - Adagio (c.32-39) Max Reger

Além do mais, similar à Sarabanda da Suíte no 6 de Bach, nota-se que Reger emprega, em muitos momentos, colcheias ligadas em pares. $O$ uso dessa figuração constitui-se na maneira empregada por Reger de estruturar as longas frases do romantismo tardio sem se distanciar do padrão métrico da sarabanda, com apoio no segundo tempo do compasso ternário que, nesse caso, é induzido pelo uso das chaves de crescendo e decrescendo. 
Bach, por sua vez, emprega a semínima em um compasso ternário, cuja unidade de tempo é a mínima (3/2). Ao comentar a Sarabanda da Suíte no 6 de Bach, TODD (2007, p.40, tradução nossa) sustenta que "enquanto a sua primeira metade apresenta o mais óbvio uso de ritmo convencional da sarabanda, a segunda metade apresenta um claro distanciamento do padrão rítmico convencional". ${ }^{12}$

Pode-se afirmar que ambos exercem de maneira magistral a liberdade de criação, uma vez que modificam a maneira com que a sarabanda usualmente é escrita, mas, ao mesmo tempo, usam técnicas composicionais que remetem à mesma (Ex.13a, 13b).

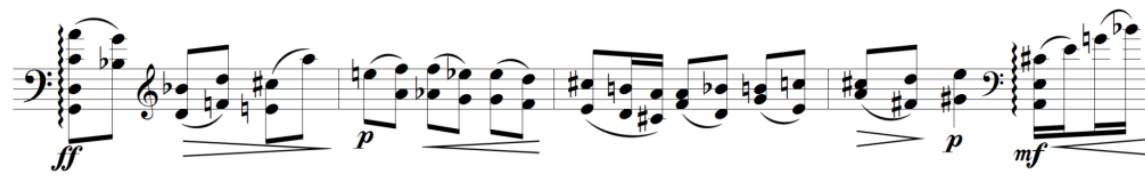

Ex.13a - Suíte para violoncelo solo 131c № 1 - Adagio (c.16-19) Max Reger

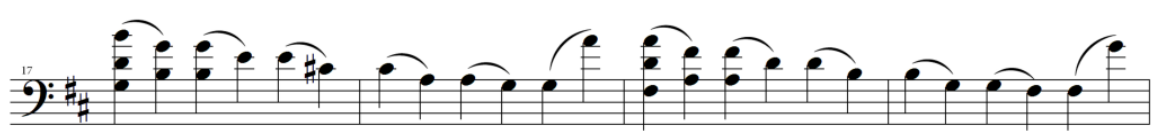

Ex.13b - Suíte para violoncelo solo BWV 1012 - Sarabanda (c.17-20) J.S. Bach

Porém, ao contrário das Sarabandas nas suítes de Bach, escritas em forma binária, verifica-se que o Adagio de Reger está estruturado na forma ABA modificada. Nota-se que os oito compassos iniciais se repetem a partir do c.41, após uma seção interna, de caráter contrastante, delineando assim uma forma ABA'.

FRISH (2004, p.740, itálico e tradução nossa), ao comentar o adágio da Suíte para Órgão em Mi menor, Op. 16, de Reger, afirma que "o mais intrigante movimento histórico na suíte é o adágio, em forma ABA' - característica de um movimento lento clássico-romântico". ${ }^{13}$ De maneira semelhante, na Suíte para violoncelo solo № 1, Reger adota a forma ABA' tanto para o Präludium quanto para o Adagio (Ex.14).

\begin{tabular}{|c|c|c|c|}
\hline Seções & A & B & A' $^{\prime}$ \\
\hline Compassos & $1-14$ & $14-40$ & $41-83$ \\
\hline
\end{tabular}

Ex.14: Tabela - Estrutura do Adagio

Interessante ressaltar que Reger inicia o movimento a partir de uma frase irregular de sete compassos, ao contrário da prática barroca. Nesse sentido, ao comentar as sarabandas italianas e alemãs, HUDSON (acesso em 04 março 2011, tradução nossa) afirma que "elas são caracterizadas por um afeto intenso e sério, apesar de algumas serem gentis e graciosas, e escritas em 
métrica ternária lenta, com um forte senso de equilíbrio baseado em frases de quatro compassos". ${ }^{14}$ Dessa forma, Reger adapta o caráter da sarabanda à sua própria estética musical (Ex.15).

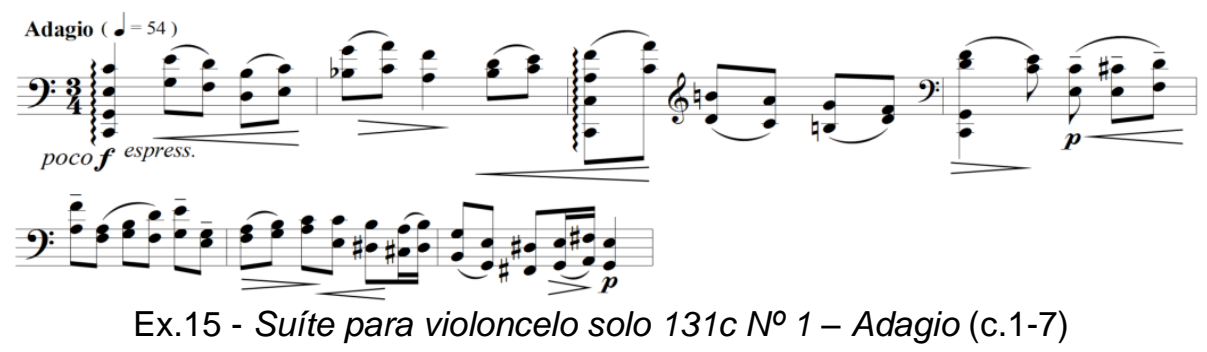

\section{Terceiro Movimento: Fuge (Allegro)}

A Suíte $n^{\circ} 1$ conclui com uma elaborada fuga, cuja indicação de andamento é Allegro. Destaca-se que a própria obra de Max Reger atesta o fascínio que o mesmo sentia pela escrita contrapontística da fuga. Como afirma GRIM (1988, p.5, tradução nossa), "Fugas, cânones, e formas não imitativas de contraponto são abundantes na obra de Reger, no entanto, o compositor não era um imitador submisso das práticas contrapontísticas de Bach". ${ }^{15}$ A título de exemplo, cita-se a Fantasia e Fuga sobre BACH, Op. 46 para órgão, ou as Variações e Fuga sobre um tema de Mozart, Op. 132 para orquestra sinfônica.

Retornando ao modelo das Seis Suítes de Bach, ressalta-se que, a Suíte BWV 1011 tem como primeiro movimento um Prelúdio na forma de abertura francesa, composta por uma introdução lenta em compasso $4 / 4$, seguido de uma fuga em 3/8. Segundo GITTER (2009, p.5, tradução nossa) "a primeira fuga para violoncelo solo que se conhece está contida dentro do Prelúdio da Suíte No. 5 em Dó menor, BWV.1011, de J.S. Bach". ${ }^{16}$

Na realidade, no caso da Suíte № 5 de Bach, considera-se o trecho a partir do c.27 até o final desse prelúdio uma "suposta ou pseudo fuga", pois o mesmo tem o esquema tonal e estrutura formal similar ao de uma fuga. No entanto, por ser escrita para um instrumento melódico, a sustentação simultânea de diversas vozes torna-se quase impossível. Neste sentido, GITTER (2009, p.7, tradução nossa) comenta:

\footnotetext{
Existem muitas razões para a rara aparição de fugas na literatura do violoncelo solo. A primeira e mais óbvia razão é que o violoncelo é principalmente um instrumento monofônico, apesar de que múltiplas linhas musicais podem ser sustentadas por pequenos períodos de tempo por meio do uso de cordas duplas e transferência de registro. ${ }^{17}$
}

Por outro lado, CAMPOS (2010, p.117) afirma que "a segunda seção da abertura francesa trata-se de uma fuga real, pois a resposta do sujeito preserva a exata relação intervalar apresentada pelo sujeito. Desta forma, a fuga está construída a quatro vozes".

Porém, como atesta GITTER (2009, p.1, tradução nossa), "ao endereçar a fuga como um gênero para violoncelo solo, Johann Sebastian Bach (1685-1750) e 
Max Reger (1873-1916) usaram princípios formais similares, resultando em diferentes peças musicais". ${ }^{18}$

Podem-se visualizar esses princípios formais na comparação entre os sujeitos de cada fuga (Ex. 16a, 16b).

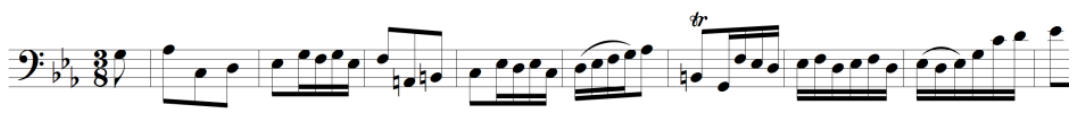

Ex.16a - Suíte para violoncelo solo BWV 1011 - Prelúdio (c.27-36)

J.S. Bach

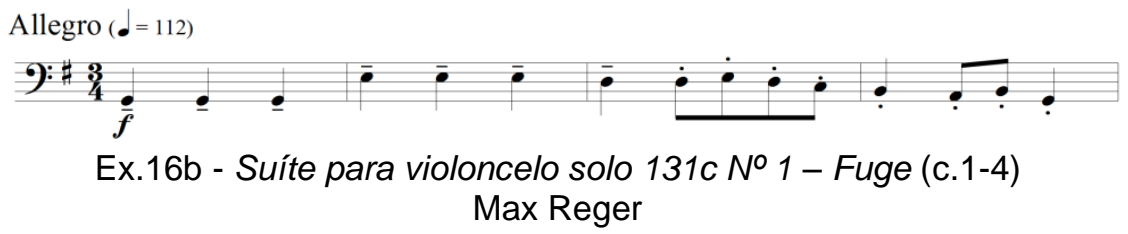

O esquema tonal de Bach é o tradicional $\mathrm{i}-\mathrm{V}-\mathrm{i}-\mathrm{V}$, sendo que a tonalidade inicial da fuga é Dó Menor. Curiosamente, a Fuge de Reger está escrita em compasso $3 / 4$ e na tonalidade de Sol Maior, tendo também por esquema tonal I-V. Entretanto, logo após as entradas em Sol Maior (c.1) e em Ré Maior (c.5), Reger inicia as transposições com entradas em Mi Maior (c.13) e em Si Maior (c.17).

Observa-se que Bach constrói a fuga que está inserida no Prelúdio da Suíte BWV 1011 sobre a tonalidade menor e Reger compõe o movimento Fuge sobre a tonalidade maior. Todavia, ambas têm como resposta ao sujeito a chamada "resposta real", ou seja, não há nenhum ajuste melódico nas respostas das respectivas fugas. Além do mais, como diz GITTER (2009, p.31, itálico e tradução nossa), "Reger usa muitas das técnicas que eram encontradas no desenvolvimento fugal de Bach. ${ }^{19}$ Entretanto, ao contrário de Bach, Reger realmente escreve o contra-sujeito simultaneamente ao sujeito, o que resulta numa fuga para um instrumento melódico com o uso constante de cordas duplas. Nota-se, portanto, grande diferença de textura ao se comparar as duas fugas (Ex.17a, 17b).

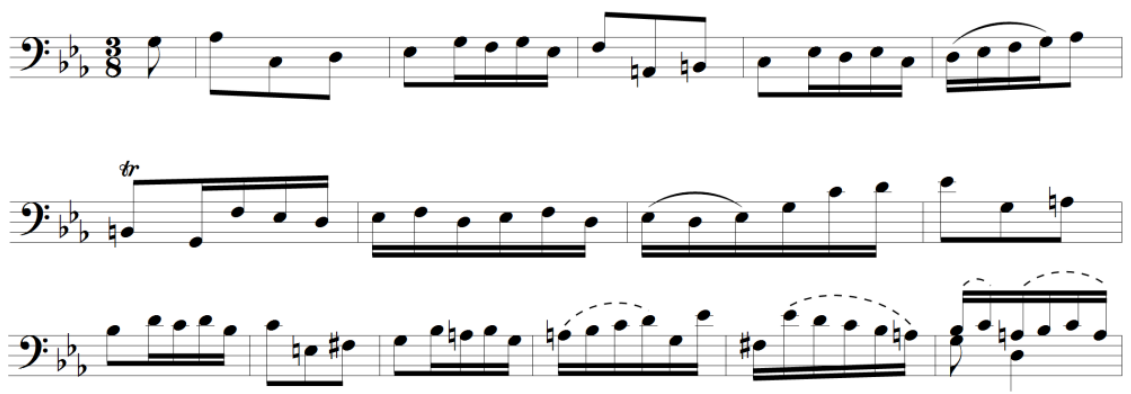

Ex.17a - Suíte para violoncelo solo BWV 1011 - Prelúdio (c.27-42) J.S. Bach 


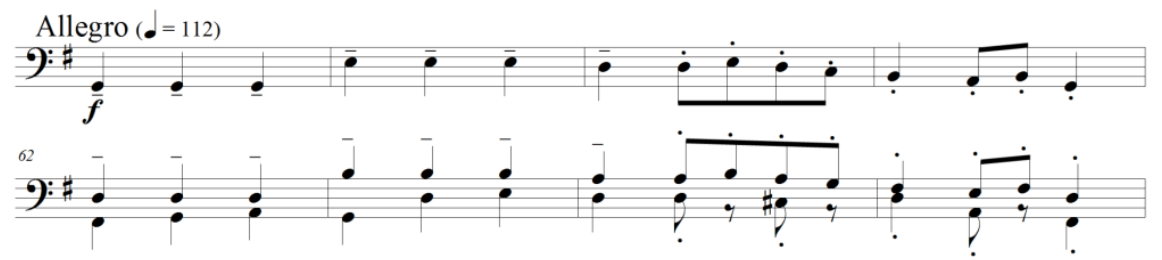

Ex.17b - Suíte para violoncelo solo 131c № 1 - Fuge (c.1-8) Max Reger

No que diz respeito à escolha do tempo dos movimentos, a fuga da Suíte para violoncelo solo BWV 1011 de Bach é tocada em andamento Allegro (Tres-vite, de acordo com o manuscrito para alaúde). CAMPOS (2010, p.117) comenta que "como segunda seção da abertura francesa, a fuga é naturalmente mais rápida que a primeira seção - esta solene e bastante introspectiva". Por sua vez, Reger coloca como indicação de andamento o termo Allegro.

Da mesma maneira, a dificuldade técnica devido ao uso de múltiplas vozes é patente nas duas fugas. A obra de Reger faz certamente uso de mais recursos técnicos que a de Bach. Ele explora praticamente toda a tessitura do violoncelo, com amplo emprego de múltiplas vozes.

Interessante notar que é possível traçar um paralelo entre a Fuga da Sonata no 1 para Violino Solo em Sol Maior de Bach com a Fuge de Reger, no que diz respeito à construção do sujeito, com notas repetidas e articulações similares. Considera-se também que existe certa similaridade entre o desenho melódico do compasso no 4 em Reger (Si-Lá-Si-Sol) com o final do compasso no 1 e início do compasso no 2 da Sonata para Violino de Bach (Ré-Dó-Si-Dó).

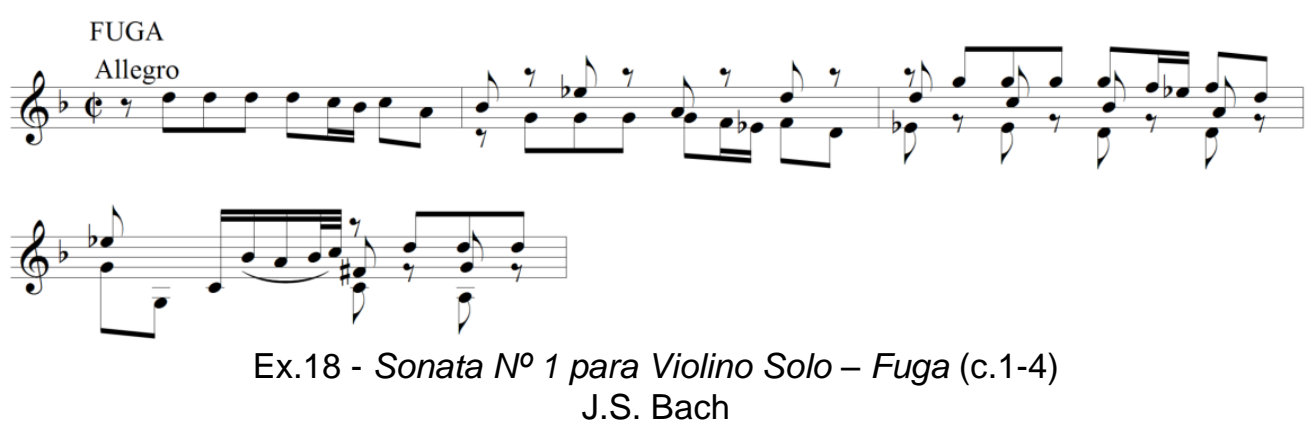

No entanto, apesar das similaridades entre a Fuge de Reger e movimentos de Bach - tanto das Suítes para Violoncelo Solo ou a Fuga da Sonata no 1 para Violino Solo - não é possível afirmar categoricamente que o compositor segue Bach como modelo estrito. Mesmo que se trace uma comparação apenas entre a Fuge de Reger com a Fuga do Prelúdio da Suíte no 5 BWV 1011, ressaltando-se que o compositor é comprovadamente atraído pela escrita de Bach, Reger igualmente se impõe através de sua própria linguagem. Como nos diz BOTSTEIN (2004, p.621, tradução nossa) "Reger voltava-se em direção a Bach". Além disso, este conclui que "A gravidade, densidade e religiosidade de Bach atraíam Reger". ${ }^{20}$ Ainda assim, a Fuge, com todos os recursos técnicos usados por Reger, traduz-se em obra única e representativa da produção do compositor. 


\title{
5. Conclusão
}

A análise da Suíte Op. 131 c no 1 de Reger, notadamente em comparação com as Suítes de J. S. Bach, conduz o leitor à conclusão de que Reger é um grande admirador do mestre do Barroco, no entanto, engajado na estética do romantismo alemão da virada dos séculos XIX e XX. Esse fato, certamente, coloca Reger como um dos precursores da corrente neoclássica do séc. XX. O intérprete, portanto, deve levar em consideração, efetivamente, os gestos barrocos inseridos na obra do compositor. Esses, no entanto, devem ser interpretados dentro da estética na qual foram compostos, ou seja, com o senso do romantismo tardio remanescente em vários compositores do início do século XX.

Em seu comentário sobre as suítes de Reger para violoncelo solo, DIXON (2008, itálico e tradução nossa) afirma que:

\begin{abstract}
Enquanto cada uma dessas obras são claramente distintas das de Bach, a clareza da linha e a textura em cada uma aspiram ao ideal do alto barroco alemão. Nenhuma dessas obras chega perto de desafiar a preeminência de Bach nesses gêneros, mas elas oferecem o frescor de um olhar moderno para com a linguagem e as formas do início do século dezoito, e sem a postura autoconsciente estilística de Stravinsky ou de seus seguidores Parisienses. ${ }^{21}$
\end{abstract}

Claramente Reger se inspira em Bach, porém escreve uma obra revestida de linguagem individual, própria, e que revela sua posição diante da estética da época. Ao mesmo tempo, revisitar o gênero Suíte representa a ousadia de se escrever para este meio - o violoncelo solo - após uma lacuna de quase 200 anos que separam as Seis Suítes de J.S.Bach (c. 1717-1723) das Três Suítes de Max Reger (1914-1915).

\section{Referências}

CAMPOS, Luz. Yanaina Alvarez. Complexidade e simplicidade: paradoxo na estrutura composicional do Prelúdio da Suíte NNo. 5 para Violoncelo solo de J. S. Bach. Dissertação (Mestrado em Música). Universidade Federal da Paraíba, Centro de Ciências Humanas, Letras e Artes. 2010.

BOTSTEIN, Leon. Notes from the editor: History and Max Reger. In: The Musical Quartely, v. 87, n. 4, p.617-627, winter 2004.

BRINKMANN, Reinhold. A last giant in music: thoughts on Max Reger in the twentieth century. Tradutor: Antonius Bittmann. In: The Musical Quartely, v. 87, n. 4, p.631-659, winter 2004.

DIXON, Gavin. The chamber music of Max Reger. 2008. Disponível em: http://www.gavindixon.info/index.htm. Acesso em 17/12/2012.

FRISH, Walter. Reger's historicist modernism. In: The Musical Quartely, v. 87, n. 4, p.731-748, winter 2004.

GINSBURG, Lev. The history of the violoncello. Hebert R. Axelrod (ed.). Tradutora: Tanya Tchistyakova. New Jersey: Paganiniana Publications, 1983. 
GITTER, Benjamin David. Fugal writing for atypical instrumentation: how Johann Sebastian Bach and Max Reger approached the compositional challenge of composing a fugue for unaccompanied cello. Tese (Doctor of Musical Arts), University of Missouri-Kansas City, 2009.

GRIM, William E. Max Reger: A bio-bibliography. New York: Greenwood Press, 1988.

HUDSON, Richard. "Sarabande". In: SADIE, Stanley. The New Grove Dictionary of music and musicians. New York: Oxford University Press. Disponível em:

http://www.oxfordmusiconline.com/subscriber/article/grove/music/. Acesso em: 04 março 2011.

JOHNSTONE, David. The late-romantic German cello school - an introduction to Julius Klengel and his compositions. In: Articles, Vlc.16, [sd]. Disponível em: <http://www.johnstonemusic.com>. Acesso em: 25 março 2011.

LEDBETTER, David, FERGUSON, Howard. "Prelude". In: SADIE, Stanley. The New Grove Dictionary of music and musicians. New York: Oxford University Press. Disponível em: http://www.oxfordmusiconline.com/subscriber/article/grove/music/. Acesso em: 25 março 2011.

LITTLE, Meredith., JENNE, Natalie. Dance and the music of J. S. Bach. Bloomington: Indiana University Press, 1998.

NAGLEY, Judith., ANDERSON, Martin. "Reger (Johann Baptist Joseph) Max (Maximilain)". In: SADIE, Stanley. The New Grove Dictionary of music and musicians New York: Oxford University Press. Disponível em:

http://www.oxfordmusiconline.com/subscriber/article/grove/music/. Acesso em: 25 março 2011.

TODD, Richard. The sarabandes from J. S. Bach's Six Suites for Solo Cello: an analysis and interpretive guide for the modern guitarist. Tese (Doctor of Musical Arts) University of North Texas, May, 2007.

\section{Notas}

1 The contrapuntal aspect of much of Reger's music is a particularly distinguishing feature. Probably no other composer of the late romantic era was influenced as Reger by the music of $\mathrm{J}$. S. Bach.

2 Though he was riding on his chromatic path, to paraphrase his own words, "steadfastly to the left", he never wanted to cross the border into the new territory of atonality.

${ }^{3}$ It is he who forges a modernist language by at once retaining so much of, and yet at the same time relativizing, the musical principles of atonality.

${ }^{4}$ Apart from being recognized as fine solo and chamber performers, they were to become the most prominent cello teachers during thirty years of the twentieth century, albeit with very different teaching methods and opinions. One could say that they formed two summits of the German art of the cello.

${ }^{5}$ Reger dedicated to Klengel one of his solo suites for violoncello Op. 131, №1, and a sonata for cello and piano Op. 116. Reger also frequently performed with the cellist.

${ }^{6}$ Embora com data não identificada, é sabido que Klengel também escreveu, já no século XX, uma Suíte para violoncelo solo, em Ré menor, Op. 56. Esta obra, no entanto, não se estabeleceu no repertório do instrumento.

7 The purpose of notating improvisation was generally to provide models for students so an instructive intention, often concerned with a particular aspect of instrumental technique, remained an important part of the prelude. Because improvisation may embrace a wide range of 
manners, styles and techniques, the term was later applied to a variety of formal prototypes and to pieces of otherwise indeterminate genre.

${ }^{8}$ All six of Bach's solo cello suites contain sarabandes, and each is a unique contribution to the literature for that instrument.

9 During the late Baroque era (early 1700s), polyphony on the cello was limited primarily to slower pieces where there was time to overcome the technical challenges involved in sustaining multiples lines of music, such as in the Sarabande from the Suite No.4 in E-flat-major, BWV. 1010 for solo cello by J. S. Bach.

${ }^{10}$ His fondness for chromaticism was such that Schoenberg suspected he would soon join the ranks of the atonalists, but for Reger chromaticism was a means for expanding the resources of tonality, not a harbinger of its imminent collapse.

11 The 3/2 meter again suggests a slow, majestic performance.

12 While its first half presents the most obvious use of a conventional sarabande rhythm, the second half presents the clearest departure from the conventional rhythmic pattern.

13 The most intriguingly historicist movement in the suite is the adagio whose form is ABA'characteristic of a classical-romantic slow movement.

14 They are characterized by an intense, serious affect, though a few are tender and gracious, and are set in slow triple metre (sic) with a strong sense of balance based on four-bar-phrases.

${ }^{15}$ Fugues, canons, and non-imitative forms of counterpoint abound in Reger's ouvre, yet the composer was not a slavish imitator o Bachian contrapuntal practices.

${ }^{16}$ The earliest known fugue for solo cello is contained within the Prelude of the Suite No. 5 in C minor, BWV.1011, by J.S.Bach.

17 There are several reasons for the rare appearance of fugues within the solo cello literature. The first and most obvious reason is that the cello is mostly a monophonic instrument, although multiple lines of music can be sustained for short times through the use of double stops and registral transfer.

18 Johann Sebastian Bach (1685-1750) and Max Reger (1873-1916), used similar formal principles resulting in very different pieces of music when approaching the fugue as a genre for solo cello.

${ }^{19}$ Reger uses many of the same techniques that were found in Bach's fugal development.

${ }^{20}$ Reger was drawn further back to Bach. The gravity, density and religiosity of Bach appealed to Reger.

${ }^{21}$ While each of these works is clearly distinct from Bach, the clarity of line and texture in each aspires throughout to the ideal of the German high Baroque. None of the works comes close to challenging Bach's pre-eminence in these genres, of course, but they provide a refreshing modern engagement with the language and forms of the early eighteen century, and without the self-conscious stylistic posturing of Stravinsky or his Parisian followers.

Ângela Maria Ferrari, Professora Associada do Departamento de Música da Universidade Federal de Santa Maria é responsável pela implementação do Bacharelado em Violoncelo na instituição. Com bolsa da Fundação CAPES cursou o Doutorado em Artes Musicais - na University of Miami, ganhando o Prêmio "Excellence in Academy" ao final do doutorado. É frequentemente convidada para participar de cursos e orquestras como professora e instrumentista. Nos anos de 2010 e 2011 foi professora convidada do Festival 
de Música de Londrina, PR. Em 2003 foi agraciada com a "Bolsa Virtuose" dada pelo Ministério da Cultura frequentando assim a Classe de Violoncelo do renomado solista e professor búlgaro Anatoly Krastev na Academia Nacional de Sofia - Bulgária

Felipe Avellar de Aquino é Professor Associado do Departamento de Música da Universidade Federal da Paraíba, onde leciona Violoncelo e Música de Câmera. Foi fundador e primeiro Coordenador do Programa de Pós-Graduação em Música da UFPB. Realizou curso de Mestrado em Música (Violoncelo) na Louisiana State University e Doutorado na Eastman School of Music (Nova York), como também é membro da The Honor Society of Phi Kappa Phi e da Society of Pi Kappa Lambda. Atua como camerista e solista, tendo se apresentado no Brasil, Argentina, Itália, Estados Unidos e Canadá. Além das atividades de performance, tem desenvolvido pesquisas sobre a técnica e literatura violoncelística, com artigos publicados nas Revistas Opus, Per Musi e The Strad (Inglaterra). 